\title{
Soil erosion in an avalanche release site (Valle d'Aosta: Italy): towards a winter factor for RUSLE in the Alps
}

\author{
S. Stanchi ${ }^{1,2}$, M. Freppaz ${ }^{1,2}$, E. Ceaglio ${ }^{3}$, M. Maggioni ${ }^{1,2}$, K. Meusburger ${ }^{4}$, C. Alewell ${ }^{4}$, and E. Zanini ${ }^{1,2}$ \\ ${ }^{1}$ University of Turin, Department of Agriculture, Forest and Food Sciences (DISAFA), Largo Braccini 2, Grugliasco, \\ TO 10095, Italy \\ ${ }^{2}$ University of Turin, NATRISK, Research Centre on Natural Risks in Mountain and Hilly Environments, Largo Braccini 2, \\ Grugliasco, TO 10095, Italy \\ ${ }^{3}$ Fondazione Montagna Sicura - Montagne Sûre, Villa Cameron, Località Villard de la Palud, 1, \\ 11013 Courmayeur (AO), Italy \\ ${ }^{4}$ Environmental Geosciences, University of Basel, Bernoullistr. 30, 4056 Basel, Switzerland
}

Correspondence to: S. Stanchi (silvia.stanchi@unito.it)

Received: 27 November 2013 - Published in Nat. Hazards Earth Syst. Sci. Discuss.: 11 February 2014 Revised: 26 May 2014 - Accepted: 6 June 2014 - Published: 16 July 2014

\begin{abstract}
Soil erosion in Alpine areas is mainly related to extreme topographic and weather conditions. Although different methods of assessing soil erosion exist, the knowledge of erosive forces of the snow cover needs more investigation in order to allow soil erosion modeling in areas where the snow lays on the ground for several months. This study aims to assess whether the RUSLE (Revised Universal Soil Loss Equation) empirical prediction model, which gives an esti-

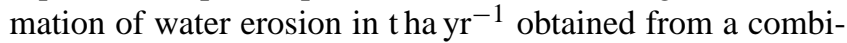
nation of five factors (rainfall erosivity, soil erodibility, topography, soil cover, protection practices) can be applied to mountain areas by introducing a winter factor $(W)$, which should account for the soil erosion occurring in winter time by the snow cover. The $W$ factor is calculated from the ratio of Ceasium-137 $\left({ }^{137} \mathrm{Cs}\right)$ to RUSLE erosion rates. Ceasium137 is another possible way of assessing soil erosion rates in the field. In contrast to RUSLE, it not only provides waterinduced erosion but integrates all erosion agents involved. Thus, we hypothesize that in mountain areas the difference between the two approaches is related to the soil erosion by snow. In this study we compared ${ }^{137} \mathrm{Cs}$-based measurement of soil redistribution and soil loss estimated with RUSLE in a mountain slope affected by avalanches, in order to assess the relative importance of winter erosion processes such as snow gliding and full-depth avalanches. Three subareas were considered: DS, avalanche defense structures, RA, release area, and TA, track area, characterized by different prevalent
\end{abstract}

winter processes. The RUSLE estimates and the ${ }^{137} \mathrm{Cs}$ redistribution gave significantly different results. The resulting ranges of $W$ evidenced relevant differences in the role of winter erosion in the considered subareas, and the application of an avalanche simulation model corroborated these findings. Thus, the higher rates obtained with the ${ }^{137} \mathrm{Cs}$ method confirmed the relevant role of winter soil erosion. Despite the limited sample size (11 points), the inclusion of a $W$ factor in RUSLE seems promising for the improvement of soil erosion estimates in Alpine environments affected by snow movements.

\section{Introduction}

Soil erosion hazard largely affects mountain areas worldwide (JRC, 2009), and particularly environments subject to natural and anthropogenic disturbance (Litschert et al., 2014).

While the causes and effects of erosion as a soil degradation threat in the world are widely described and investigated (Lal, 2001), soil loss estimation in sloping areas still has some uncertainties, as the methods commonly used are not specifically designed for mountain environments, where climate and relief are extreme (Alewell et al., 2008; Garcia Rodriguez et al., 2012). Recently, the relevance of winter erosion processes, besides the ones taking place in the growing season, has been pointed out. For example, Ceaglio et 
al. (2012), and more recently Korup et al. (2014), proved that snow movements are a significant agent of soil redistribution at mountain sites. Within these snow movements, wet avalanches are well known for their high sediment yields (Gardner, 1983; Ackroyd, 1987; Bell et al., 1990; Jomelli and Bertran, 2001; Heckmann et al., 2005); however, so far regionalization and parameterization of these processes are missing.

Soil erosion can be estimated on different spatial and temporal scales using different models. An exhaustive review is provided by De Vente and Poesen (2005), who underlined the fact that the existing approaches consider a variety of parameters, but none of them fulfills all modeling objectives. One of the most commonly applied methods for soil erosion estimation is the Revised Universal Soil Loss Equation (RUSLE) derived from USLE (Wischmeier and Smith, 1978), which has received considerable improvements after the introduction of geographic information systems and has been then applied to a large variety of environments (Desmet and Govers, 1996; Prasannakumar et al., 2012; Prasuhn et al., 2013; Zhang et al., 2013). The RUSLE model provides an estimate of long-term average water soil erosion rate in tha $\mathrm{yr}^{-1}$, which is obtained by multiplying five factors $(R$, rainfall erosivity; $K$, soil erodibility, LS, topography; $C$, vegetation cover; $P$, soil protection practices). However, the erosion rate derived from RUSLE corresponds to water erosion and cannot consider snow-induced erosion, which may indeed be a relevant part of the total soil loss in mountain areas. According to the USLE procedure, snowmelt might theoretically be included in the rainfall erosivity factor computation, considering the snow-water equivalent data. However, as the spatial and temporal heterogeneity of the snow cover is considerable (Lopez Moreno et al., 2013) and the snowmelt processes may show significant time pulsations, it is difficult to obtain a satisfactory conversion of snowfall into liquid precipitation equivalents. Therefore, the USLE model offers only an insufficient parameterization of the snow effect. A first try at considering the winter erosion processes in the USLE is the work by Konz et al. (2009), who suggested the development of an "Alpine USLE" that includes an Alpine factor $W$ implemented for slopes that are prone to avalanches and snow gliding processes. They found that soil loss estimates for mountain areas often show significant deviations from field-measured data obtained during the growing season on snow-free soil (Konz et al., 2009).

This finding suggests that more complex phenomena are driving soil erosion in mountain environments and that erosion in areas seasonally snow covered might be affected considerably by other agents of soil erosion. For example, Confortola et al. (2012) observed that snow avalanches, characterized by high velocity, and snow gliding processes, i.e., the slow downhill movement of the snow cover on smooth and/or wet ground, are relevant erosion agents in the Alps. Besides soil erosion modeling, soil erosion rates can be obtained from sediment collection in the field. A method based on field data to derive erosion rates from field measurements makes use of fallout radionuclides like Caesium-137 $\left({ }^{137} \mathrm{Cs}\right) .{ }^{137} \mathrm{Cs}$ is an anthropogenic isotope that originated from the testing of thermonuclear weapons and the Chernobyl accident. When ${ }^{137} \mathrm{Cs}$ fallout reaches the soil surface, it is tightly adsorbed to fine soil particles (Tamura, 1964; Tamura and Jacobs, 1960). Thus, its subsequent redistribution is associated with soil redistribution (Ritchie and McHenry, 1990). The ${ }^{137}$ Cs method has the major advantage of reflecting all erosion processes by water, snow and wind, and is thus an integrated estimate of the total net soil redistribution rate since the 1950s (the start of the global fallout deposit) and since 1986 (in areas where the major fallout originated from the Chernobyl accident). Fallout radionuclides are therefore largely used to assess the budget of soil erosion and sedimentation processes (Mabit et al., 2008; Mabit and Bernard, 2007; Matisoff and Whiting, 2011; Mabit et al., 2013). Ceaglio et al. (2012) used this method to compare field-measured and ${ }^{137} \mathrm{Cs}$-derived soil redistribution rates, highlighting the predominance of the snow-related phenomena in the total soil erosion for a mountain basin in the northwestern Italian Alps.

Because of the different soil erosion processes and timescales considered, ${ }^{137} \mathrm{Cs}$ soil erosion estimates are often not directly comparable with RUSLE estimates. In mountain areas the deviations between RUSLE and available measurements have been commonly attributed to an intrinsic unsuitability of the model for steep and complex topography, but they might also depend on the presence of relevant snowdriven erosion phenomena that are not included in the rainfall erosivity factor $(R)$ of RUSLE (Konz et al., 2009).

The potential phenomena that could generate soil erosion on a snow-covered slope are avalanches and snow gliding. Flowing avalanches can produce considerable soil removal and sediment transport both in the release and track zones (Confortola et al., 2012), altering the soil morphology on the local scale, transporting a significant amount of soil across the runout zone (Sass et al., 2010). If full-depth avalanches predominate, and the avalanche flows interact directly with the soil surface, the soils can be stripped off in the track zone and can be fragmented and/or highly degraded (Freppaz et al., 2006, 2010). Complex soil profile morphologies may occur along an avalanche path with both buried and truncated soil horizons. Snow gliding phenomena can contribute significantly to soil erosion at the snow-soil interface as shown by Meusburger et al. (2014), who identified snow gliding as a relevant driver for winter soil erosion in the Swiss Alps. Despite the first try by Konz et al. (2009) at including a winter factor in the RUSLE, the incidence of snow-induced erosion on large scales (e.g., catchment or avalanche areas) cannot be evaluated with a well-defined standard procedure.

The general aim of the present research is to compare ${ }^{137}$ Cs-based soil redistribution rates and soil loss estimated with the RUSLE model in a mountain slope affected by snow gliding and glide-snow avalanches. We will investigate sites where we expect different intensities of snow-induced 
erosion: the release area (RA), where avalanche release and slow snow cover movements take place; the track area (TA) directly affected by the avalanche run; and a third area, protected by avalanche defense structures (DS) that are designed to reduce snow cover movements, where avalanche release is excluded but slow snow cover movements can still occur. The specific objectives are (1) to apply the GIS-based RUSLE at a mountain site affected by recurrent glide-snow avalanches, (2) to compare the soil erosion estimates of the RUSLE with the ${ }^{137} \mathrm{Cs}$-based erosion rates estimated from a previous field survey carried out by Ceaglio et al. (2012), (3) to test a winter correction factor (winter factor, $W$ ) calculated from the ratio of Ceasium-137 ( ${ }^{137} \mathrm{Cs}$ ) to RUSLE erosion rates, referring to winter soil erosion contribution, and (4) to discuss and interpret the results also considering a 2-D avalanche dynamic model proposed by Christen et al. (2010).

\section{Materials and methods}

\subsection{Study area}

The study area is an avalanche site named Mont de la Saxe located in the northwestern part of the Valle d'Aosta region (northwestern Italy, Fig. 1a), very close to the southern side of the Mont Blanc massif (4810 m a.s.1.). The avalanche site (24.6 ha, Fig. 1b) ranges from $2115 \mathrm{~m}$ to $1250 \mathrm{~m}$ a.s.l. Three subareas were considered (RA, release area; TA, track area; DS, avalanche defense structure area), where 11 sampling points were chosen. While choosing sample points for this study, areas affected by complete topsoil removal were excluded.

The geology is characterized by black argillic schists, calcareous sandstones and a limited portion of porphyritic granites, very similar to that of the Mont Blanc area. The site is affected by glide-snow avalanches occurring in springtime or late autumn, and is prone to snow gliding and subsequent glide crack formation. Soil erosion is very pronounced and clearly related to snow-soil interface dynamics (Ceaglio et al., 2012), as soil is frequently removed by avalanches and large soil deposits can be observed in the avalanche runout area. In the last four years, glide-snow avalanches have been documented almost yearly. Most of the area is Alpine pasture, with patches of dwarf shrubs. The avalanche release area (RA) is an abandoned pasture located at $2100 \mathrm{~m}$ a.s.1. (steepness $30-35^{\circ}$ ). Avalanche defense structures (DS) are present close to this area, on similar slopes, and the protected surface is colonized by dwarf shrubs and larch seedlings. The avalanche track area (TA) ranges from 2000 to $1350 \mathrm{~m}$ a.s.1. and is characterized by the presence of different channels, with grass cover or bare soil and rock outcrops in the steepest sections. The runout area starts at $1200 \mathrm{~m}$ a.s.1., ends on an avalanche shed protecting the road and is characterized by decreasing slope steepness. An exhaustive description of the avalanche site and dynamics, as well as the sampling strategy in the area, is provided by Ceaglio et al. (2012).

\subsection{Soil properties}

In general, soils in the study area are shallow and scarcely developed.

The upper soil horizons had a sand content ranging from 32 to $60 \%$, and a clay content ranging from 6 to $20 \%$ (Ceaglio et al., 2012). The soil bulk density ranged between $0.66 \mathrm{Mg} \mathrm{m}^{-3}$ (SB) and $1.07 \mathrm{Mg} \mathrm{m}^{-3}$ (RA), and the skeleton content from 5 to $44 \%$ (Ceaglio et al., 2012). The organic carbon content (data not shown) was higher in DS $(4.9 \%)$ and lower in RA $(3.3 \%)$ and TA $(3.8 \%)$, suggesting an enrichment of organic matter after the development of seedlings and dwarf shrubs in the DS area. Soil properties in the study area are reported in detail by Ceaglio et al. (2012). As visible in Fig. 2, several erosion features were observed, such as sheet erosion and removal of vegetation cover in the avalanche release and track areas.

\subsection{Caesium-137 derived soil redistribution}

A Li-drifted Ge detector with a $20 \%$ relative efficiency (GeLi; Princeton Gamma-Tech, Princeton, NJ, USA) was used for gamma spectroscopy. The resulting measurement uncertainty in the ${ }^{137} \mathrm{Cs}$ peak area (at $662 \mathrm{keV}$ ) was lower than $8 \%$ (error of the measurement at 1-sigma). Gamma spectrometry calibration and quality control were performed following the protocol proposed by Shakhashiro and Mabit (2009). The methods and instruments used are detailed in Ceaglio et al. (2012). Soil samples were collected during the summer season of 2010, using a $72 \mathrm{~mm}$ diameter soil core sampler (Giddings Machine Company, Windsor, CO, USA). Caesium-137 activity was measured at eleven points in the three subareas: (a) the avalanche defense structures (DS), the avalanche release area (RA), and the avalanche track area (TA) (Fig. 1). For the reference inventories eleven points located very close to the study area in a flat and undisturbed position (2000 m a.s.l.) were sampled. The depth distribution of ${ }^{137} \mathrm{Cs}$ was determined in $5 \mathrm{~cm}$ depth increments. To convert inventories into soil redistribution rates, the profile distribution model, which is the most commonly used conversion model for undisturbed soils, was used (Walling and Quine, 1990). In undisturbed soils the ${ }^{137} \mathrm{Cs}$ distribution shows an exponential decrease with depth, which is described by the following function (Walling and Quine, 1990; Zhang et al., 1990):

$A^{\prime}(x)=A_{\text {ref }}\left(1-e^{x / h_{o}}\right)$,

where $A^{\prime}(x)=$ amount of ${ }^{137} \mathrm{Cs}$ above the depth $x\left(\mathrm{~Bq} \mathrm{~m}^{-2}\right)$; $x=$ depth from soil surface expressed as mass between top and actual depth $\left(\mathrm{kg} \mathrm{m}^{-2}\right) ; A_{\text {ref }}={ }^{137} \mathrm{Cs}$ reference inventory $\left(\mathrm{Bqm}^{-2}\right)$; and $h_{o}=$ profile shape factor $\left(\mathrm{kg} \mathrm{m}^{-2}\right)$. It is a 


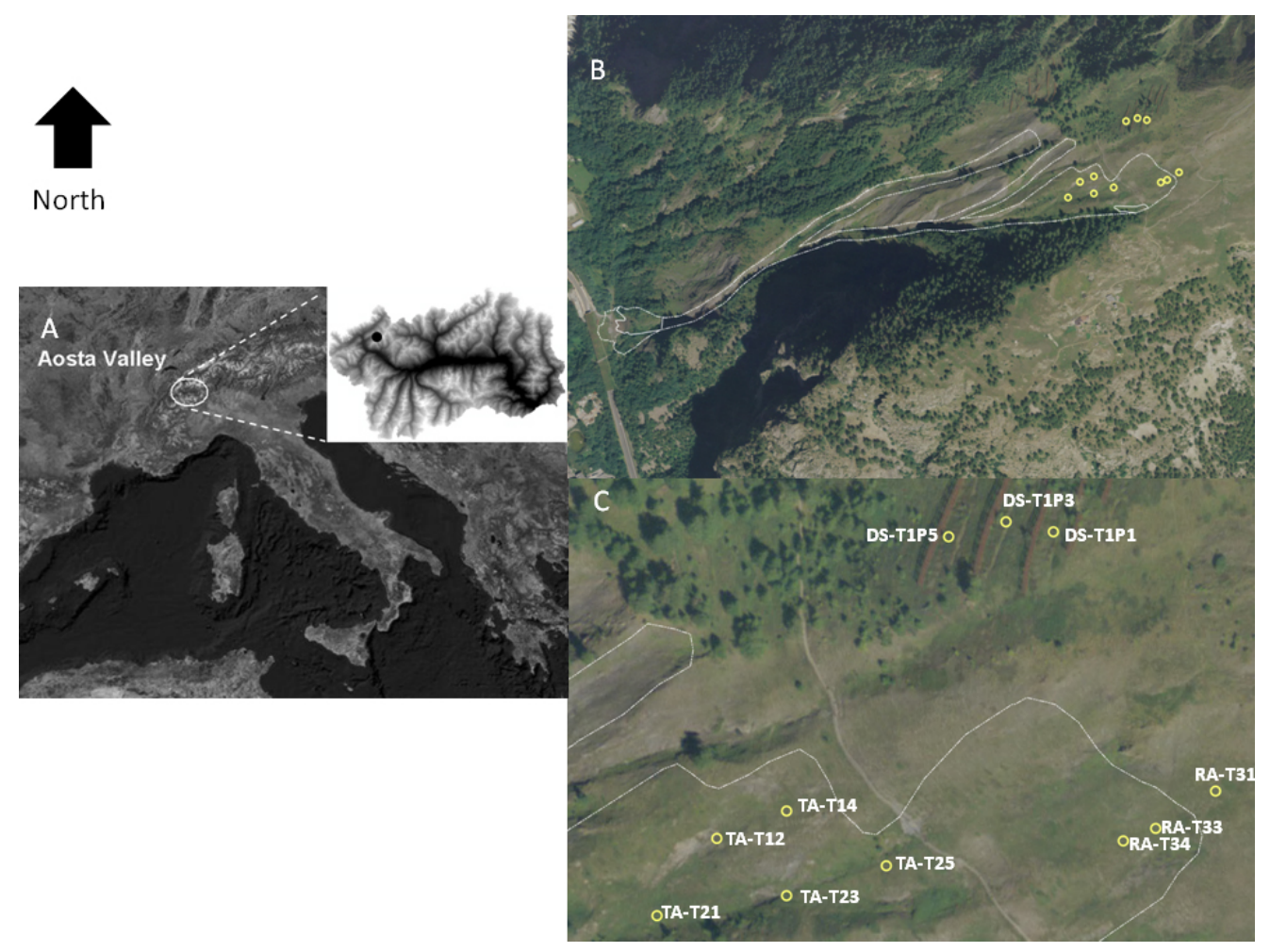

Figure 1. Study area: (A) site location within Italy and the Valle d'Aosta region; (B) avalanche area and sampling points and (C) sampling points in detail. DS: defense structures area; TA: track area; RA: release area.

coefficient describing the rate of exponential decrease in inventory with depth, for soil profiles at $u$ sites.

If it is assumed that the total ${ }^{137} \mathrm{Cs}$ fallout occurred in 1986 and that the depth distribution of the ${ }^{137} \mathrm{Cs}$ in the soil profile is independent of time, the erosion rate $Y$ for an eroding point (total ${ }^{137} \mathrm{Cs}$ inventory $A_{\mathrm{u}}\left(\mathrm{Bq} \mathrm{m}^{-2}\right)$ less than the local reference inventory $A_{\text {ref }}\left(\mathrm{Bq} \mathrm{m}^{-2}\right)$ ) can be expressed as (Walling and Quine, 1990; Zhang et al., 1990)

$Y=10 /(t-1986) \times \ln (1-X / 100) \times h_{o}$,

where $Y=$ soil erosion rate $\left(\mathrm{tha}^{-1} \mathrm{yr}^{-1}\right) ; t=$ year of sampling; 1986 because in the Valle d'Aosta region the contribution of Chernobyl wet deposition constituted the major part of the global inventory ( $84 \%$ according to Facchinelli et al., 2002); $X=\%$ reduction of ${ }^{137}$ Cs total inventory with respect to the local ${ }^{137} \mathrm{Cs}$ reference value (defined as $\left.\left(A_{\text {ref }}-A_{\mathrm{u}}\right) / A_{\text {ref }} \times 100\right)$.

\subsection{RUSLE-derived soil erosion and winter factor calculation}

The Revised Universal Soil Loss Equation (RUSLE) model is formulated as follows:

$A=R \times K \times \mathrm{LS} \times C \times P$,

where $A=$ predicted average annual soil loss $\left(\mathrm{tha}^{-1} \mathrm{yr}^{-1}\right)$; $R=$ rainfall-runoff-erosivity factor $\left(\mathrm{MJ} \mathrm{mm} \mathrm{ha}{ }^{-1} \mathrm{~h}^{-1} \mathrm{yr}^{-1}\right.$ ) that quantifies the effects of raindrop impact and reflects the rate of runoff likely to be associated with the rain (Wischmeier and Smith, 1978); $K=$ soil erodibility factor (thah $\mathrm{MJ}^{-1} \mathrm{ha}^{-1} \mathrm{~mm}^{-1}$ ) that reflects the ease with which the soil is detached by the impact of a splash or surface flow; LS accounts for the effect of slope length $(L)$ and slope gradient $(S)$ on soil erosion (dimensionless); $C=$ cover factor (dimensionless), which represents the effects of all interrelated cover and management variables (Renard et al., 1997); and $P=$ (dimensionless) is the support practice factor.

The $R, K$, and LS factors basically determine the erosion volume, while the $C$ and $P$ factors are reduction factors ranging between 0 and 1 .

RUSLE was applied for the eleven sites (Fig. 1), where ${ }^{137} \mathrm{Cs}$ estimates were also available. The $R$ factor was taken from Bazzoffi (2007), indicating an average of $1238 \mathrm{MJ} \mathrm{mm}$ $\mathrm{ha}^{-1} \mathrm{~h}^{-1} \mathrm{yr}^{-1}$ for the municipality of Courmayeur, where the study area is located. The adopted value is consistent with the ones reported by Meusburger et al. (2012) for the Swiss Alps and the seasonal values of rainfall erosivity produced by JRC for Italy (Grimm et al., 2000).

The $K$ factor (tha h $\mathrm{MJ}^{-1} \mathrm{ha}^{-1} \mathrm{~mm}^{-1}$ ) was calculated according to Wischmeier and Smith (1978) using the following equation adopted also by Bazzoffi (2007) for Italy: 


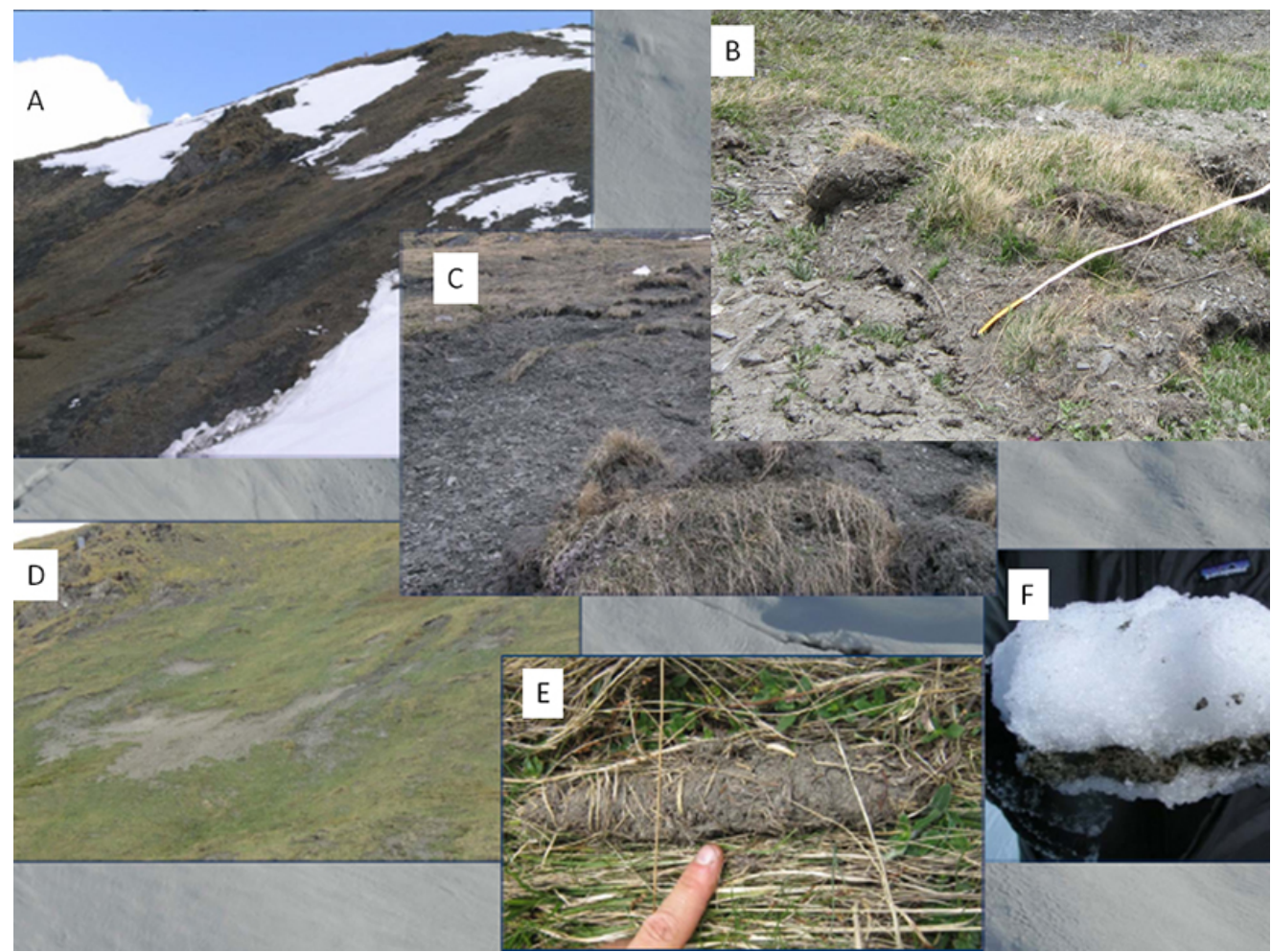

Figure 2. Evidence of erosion features in the avalanche release area. (A) view of the avalanche release area just after the snowmelt (RA); (B) a shallow landslide that occurred in winter time, under snow cover, probably as a consequence of snow glide movements; (C) zoom on soil erosion and shallow landslides in RA; (D) view of eroded surface in the summer season; (E) soil "roll" including vegetation residuals, visible after snowmelt, probably due to snow gliding; (F) soil layer included in the snow bottom layer during spring time (photos: E. Ceaglio). Soil can undergo liquefaction processes when the soil water content increases. This may result in the layer found at the bottom of the snow pack observed in $\mathbf{( F )}$.

$$
\begin{aligned}
& K=0.0013175 \times\left(\left(2.1 m^{1.14}\left(10^{-4}\right)(12-a)\right.\right. \\
& +3.25(b-2)+2.5(c-3))
\end{aligned}
$$

where $m=(($ silt $(\%)+$ very fine sand $(\%)) \times(100-$ clay $(\%)), a=$ organic matter $(\%), b=$ structure code, (1) very fine granular, (2) fine granular, (3) medium or coarse granular and (4) massive, and $c=$ profile permeability code, (1) rapid, (2) moderate to rapid, (3) moderate, (4) moderate to slow, (5) slow and (6) very slow. For the determination of the $K$ factor the values of the upper $10 \mathrm{~cm}$ of the soil were used. Soil samples were oven-dried at $40^{\circ} \mathrm{C}$, passed through a $2 \mathrm{~mm}$ sieve and homogenized. The fine material $(<2 \mathrm{~mm})$ was used for all further analysis. Total organic and inorganic carbon concentration (\%) was measured by the RC612 Multiphase Carbon and Hydrogen/Moisture Analyzer (Leco company, MI, USA). Organic matter was calculated from organic carbon content by using a conversion factor of 1.72. Grain size analysis for the parameter $m$ was done with the Malvern Mastersizer 2000 (Malvern Instruments Ltd). Here we adopted $b$ equal to 2 and $c$ equal to 3 , as soil structure was slightly developed at all the sampling points, due to slope angles and limited soil profile development, and soil permeability was estimated in the field as moderate.

The LS factor (dimensionless) was calculated from the digital elevation model ( $10 \mathrm{~m}$ grid) of the study area according to the procedure described in Desmet and Govers (1996). We adopted the equation

$$
\mathrm{LS}=(F \times C / 22.13)^{0.4} \times(\sin S / 0.0896)^{1.3},
$$

where $F$ is the flow accumulation factor (Mitasova et al., 2002), $C$ is the grid size, and $S$ is the slope angle. $F$ was calculated with the Hydrology tool of ArcGIS 9.3.

LS is the factor showing a wide range of variability in mountain areas and is highly influenced by the DEM accuracy. A general warning on LS computation is about the cell size resampling, which may affect deeply the curvature of the DEM (Buehler et al., 2011) and should therefore be avoided. In this case, the available DEM resolution was $10 \mathrm{~m}$; no resampling was done.

The $C$ factor was derived from tabular data proposed by Bazzoffi (2007) for grass and pasture vegetation cover. The $P$ factor was not applicable in the area and was therefore set equal to 1 . In order to estimate the contribution of winter erosion, we calculated a $W$ factor (as done by Konz et al., 2009 
for the Alpine factor) to be added to the RUSLE formula, as the ratio between ${ }^{137} \mathrm{Cs}$ and RUSLE-based soil erosion rates (both in $\mathrm{tha}^{-1} \mathrm{yr}^{-1}$ and therefore dimensionless):

$W={ }^{137} \mathrm{Cs} / A$.

\subsection{Avalanche modeling}

The avalanche module of the RApid Mass Movements (RAMMS) dynamical model (Christen et al., 2010), developed by the SLF of Davos (CH), was used in order to simulate the avalanche flow and in particular to calculate the friction at the flow bottom. RAMMS numerically solves a system of partial differential equations, governing the depthaveraged balance laws for mass, momentum and random kinetic energy using first- and second-order finite volume techniques. More details on the model are given in Christen et al. (2010). In this work, the Voellmy-Salm approach is used. Following this approach the total basal friction $\tau(\mathrm{Pa})$ is split into a velocity-independent dry Coulomb term that is proportional to the normal stress $\sigma(\mathrm{Pa})$ at the flow bottom (friction coefficient $\mu$ ) and a velocity-dependent turbulent friction (friction coefficient $\xi\left(\mathrm{m} \mathrm{s}^{-2}\right)$ ) (Salm, 1993):

$\tau=\mu \sigma+\frac{\rho g U^{2}}{\xi}$

where $\sigma=\rho g H \cos \phi$ with $\rho\left[\mathrm{kg} \mathrm{m}^{-3}\right]$ the snow mass density, $g$ the standard gravity $\left(\mathrm{m} \mathrm{s}^{-2}\right), H(\mathrm{~m})$ the avalanche flow height and $\varphi\left({ }^{\circ}\right)$ the local slope angle, and $U\left(\mathrm{~m} \mathrm{~s}^{-1}\right)$ is the flow velocity.

Soil erosion can occur if the shear stress exerted by the avalanche flow is larger than the critical shear for soil removal $\tau_{\mathrm{c}}[\mathrm{Pa}]$ calculated as in Clark and Wynn (2007) and later reported by Confortola et al. (2012):

$\tau_{\mathrm{c}, P \mathrm{c}}=0.49 \times 10^{0.0182 P_{\mathrm{c}}}$,

where $P_{\mathrm{c}}$ is the clay content $(\%)$.

We simulated an avalanche that is considered typical for the study site: a frequent avalanche (short return period) with a release zone between 2050 and $2100 \mathrm{~m}$ a.s.l., release height of $1 \mathrm{~m}$, release volume of $7800 \mathrm{~m}^{3}$, and friction parameters $\mu$ and $\xi$ chosen according to Gruber and Bartelt (2007) all along the path (at the location of the sampling points they are $\mu=0.26$ and $\xi=2000 \mathrm{~m} \mathrm{~s}^{-2}$ ).

We underline here that the aim of the avalanche modeling is not to simulate the real events, but to estimate the erosive power of what can be considered the most representative avalanche for the path. Therefore, the results of the simulation should be interpreted in a relative way for the different sampling points.

\section{Results and discussion}

\subsection{RUSLE-based average long-term erosion rates}

The RUSLE model for water erosion prediction was chosen, as it allows one to account for the topographic variability typical of mountain environments. Moreover, the high heterogeneity of soil properties can be taken into account in terms of the $K$ factor (soil erodibility). The RUSLE factors at the sampled points are listed in Table $1 . K$ factor values (Table 1), indicating the intrinsic soil susceptibility to water erosion, ranged from 0.005 (sample DS-T1P5, with the highest clay content) to 0.030 tha h $\mathrm{MJ}^{-1} \mathrm{ha}^{-1} \mathrm{~mm}^{-1}$ (sample DS-T1P1, lowest organic matter content). The observed range is comparable with the mapped values reported for the Aosta Valley by Grimm et al. (2000). The highest erodibility was observed in the upper part of the transect of DS and RA (Fig. 3). The $C$ factor (Table 1) was assigned as 0.02 in the DS area with dwarf shrub and seedling cover, and as 0.005 in RA and TA. The LS factor at sampling points (Table 1) ranged from 3 to 37 (both in TA). High LS values are largely documented in the literature for non-agricultural environments. For example, Meusburger et al. (2010) reported LS values in the range $0-57.5$ for a study site in the Swiss Alps with an average slope of $24.6^{\circ}$. The slope angle interval (Table 1) confirms that the area is potentially prone to both snow gliding (Leitinger et al., 2008) and glide-snow avalanches (Confortola et al., 2012). RUSLE factors $K$ and LS did not differ significantly among subareas (ANOVA). RUSLE soil erosion rates at the sampled sites (Fig. 4) ranged from close to 0 (TA-T14 and TA-T21) to $17 \mathrm{tha}^{-1} \mathrm{yr}^{-1}$ (DS-T1P1). Such values refer to the first three erosion risk classes reported by Bazzoffi (2007), i.e., negligible $\left(<1 \mathrm{tha}^{-1} \mathrm{yr}^{-1}\right)$, limited $\left(1<A<5 \mathrm{tha}^{-1} \mathrm{yr}^{-1}\right)$, and moderate soil erosion $\left(5<A<20 \mathrm{tha}^{-1} \mathrm{yr}^{-1}\right)$. Average RUSLE estimates (Fig. 4) were 10.9 $\mathrm{tha}^{-1} \mathrm{yr}^{-1}$ for DS (SD 7.3), $1.9 \mathrm{tha}^{-1} \mathrm{yr}^{-1}$ for TA (SD 1.9), and 2.2 $\mathrm{tha}^{-1} \mathrm{yr}^{-1}$ for RA (SD 1.4). The RUSLE estimates were significantly higher in DS than in the rest of the area (ANOVA, $p<0.01$ ).

\subsection{Comparison of RUSLE estimates to Ceasium-137 based soil erosion rates}

The range of ${ }^{137} \mathrm{Cs}$ estimates (Fig. 4) was -0.1 to $32 \mathrm{tha}^{-1} \mathrm{yr}^{-1}$, where the negative value observed in DST1P5 indicates a net deposition rate. Average ${ }^{137} \mathrm{Cs}$ values were 13.2 $\mathrm{tha}^{-1} \mathrm{yr}^{-1}$ for DS (SD 15.4), $11.6 \mathrm{tha}^{-1} \mathrm{yr}^{-1}$ for TA (SD 11.8), and 9.1 $\mathrm{tha}^{-1} \mathrm{yr}^{-1}$ for RA (SD 4.8). High spatial heterogeneity was observed for the ${ }^{137} \mathrm{Cs}$ erosion rates, particularly in TA and DS (Fig. 4), and this made the observed differences among estimates statistically insignificant. In TA, the high variability in ${ }^{137} \mathrm{Cs}$ estimates probably depended on the high variability of soil characteristics, as also visible from the $K$ values and the channeled topography (Fig. 3). The variability of the ${ }^{137} \mathrm{Cs}$ erosion rates in the DS 
Table 1. Input data for the calculation of RUSLE factors, and RUSLE factors at sampled points. Textural classes and SOM content were used as input data for $K$ calculation. DS: defense structures area; TA: track area; RA: release area. The considered soil depth was $10 \mathrm{~cm}$.

\begin{tabular}{llllllllll}
\hline Sample & Fine sand & Silt & Clay & SOM & $\begin{array}{l}K \\
\left(\mathrm{thah} \mathrm{MJ}^{-1}\right.\end{array}$ & $\begin{array}{l}R \\
\left(\mathrm{MJ} \mathrm{mm} \mathrm{ha}^{-1}\right.\end{array}$ & LS factor & Slope & $C$ factor \\
ID & $(\%)$ & $(\%)$ & $(\%)$ & $(\%)$ & $\left.\mathrm{mm}^{-1} \mathrm{ha}^{-1}\right)$ & $\left.\mathrm{h}^{-1} \mathrm{yr}^{-1}\right)$ & $(-)$ & $\left({ }^{\circ}\right)$ & $(-)$ \\
\hline DS-T1P1 & 5.35 & 48.7 & 12.7 & 4.9 & 0.030 & 1238 & 22.56 & 36 & 0.02 \\
DS-T1P3 & 7.4 & 45.0 & 13.0 & 5.6 & 0.026 & 1238 & 20.48 & 32 & 0.02 \\
DS-T1P5 & 6.5 & 46.9 & 16.6 & 12.0 & 0.005 & 1238 & 22.76 & 37 & 0.02 \\
TA-T12 & 7.06 & 39.7 & 8.8 & 7.2 & 0.018 & 1238 & 11.92 & 46 & 0.005 \\
TA-T14 & 6.4 & 47.9 & 12.6 & 8.7 & 0.014 & 1238 & 3.55 & 37 & 0.005 \\
TA-T21 & 9.3 & 47.3 & 12.2 & 9.4 & 0.012 & 1238 & 3.79 & 29 & 0.005 \\
TA-T23 & 8.0 & 44.6 & 10.9 & 6.7 & 0.022 & 1238 & 17.01 & 37 & 0.005 \\
TA-T25 & 7.3 & 49.9 & 13.9 & 7.1 & 0.022 & 1238 & 37.00 & 37 & 0.005 \\
RA-T31 & 6.9 & 41.6 & 10.1 & 5.1 & 0.027 & 1238 & 9.03 & 37 & 0.005 \\
RA-T33 & 5.9 & 46.0 & 12.9 & 7.9 & 0.017 & 1238 & 36.42 & 36 & 0.005 \\
RA T34 & 4.9 & 45.2 & 15.2 & 9.4 & 0.010 & 1238 & 21.11 & 29 & 0.005 \\
\hline
\end{tabular}

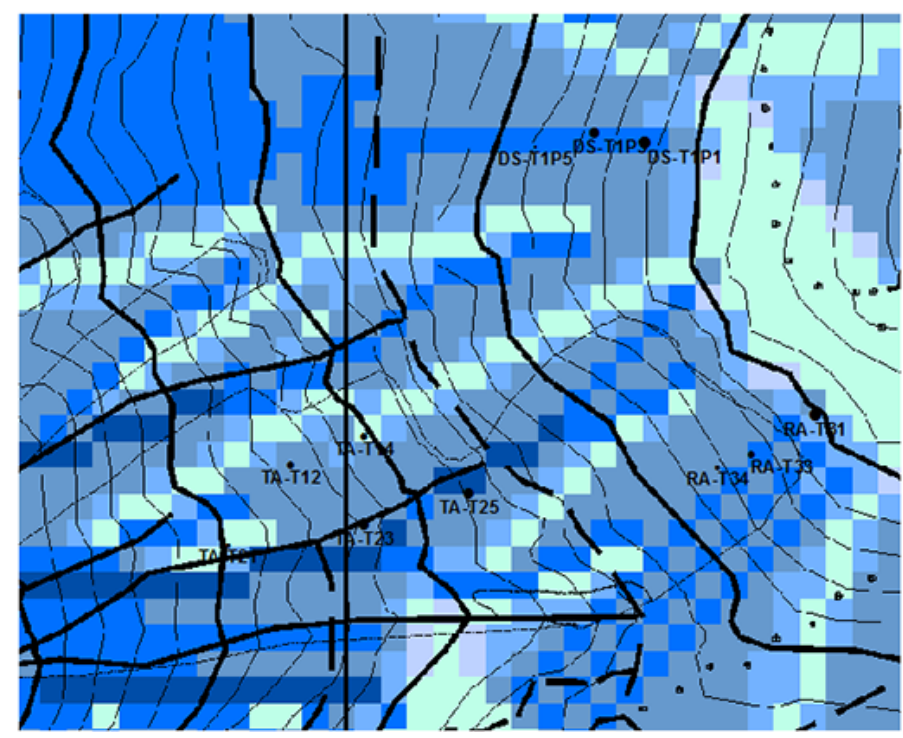

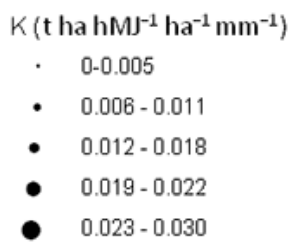

LS (-)

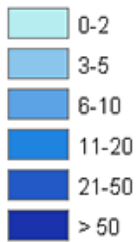

Figure 3. RUSLE LS factor map plotted on a 1:10000 topographic map. The sampling point size is proportional to the RUSLE soil erodibility factor $(K)$. The blue-colored grid represents the LS factor. DS: defense structures area; TA: track area; RA: release area.

area may rather be attributed to the simultaneous presence of erosion and deposition dynamics.

In fact, the ${ }^{137} \mathrm{Cs}$ erosion rates confirmed the importance of soil erosion in the upper portion of the DS area (Fig. 4) with $30 \mathrm{tha}^{-1} \mathrm{yr}^{-1}$ (SB-T1P1), while a sharp reduction in the net erosion rates was visible downwards, along the defense structures. At point DS-T1P3 the ${ }^{137} \mathrm{Cs}$ erosion rate dropped to $10 \mathrm{tha}^{-1} \mathrm{yr}^{-1}$, and deposition was finally observed at point DS-T1P5 (Fig. 4), indicating a net input of topsoil that was also associated with an increase in soil organic matter downwards. This can be interpreted as the result of the wooden avalanche defense structures mitigating slow snow movements, thus reducing drastically winter erosion rates. Also, RUSLE-based soil erosion rates $(A$, Fig. 4$)$ showed a decreasing trend downslope in DS, but in this case the reduction was smoother and followed the decrease in erodibility values visible from Fig. 3: $0.030 \mathrm{thah} \mathrm{MJ}^{-1} \mathrm{ha}^{-1} \mathrm{~mm}^{-1}$ (SB-T1P1, $4.9 \%$ organic matter) to $0.026 \mathrm{thah} \mathrm{MJ}^{-1} \mathrm{ha}^{-1} \mathrm{~mm}^{-1}$ (SB-T1P3, $5.6 \%$ organic matter), and finally 0.005 tha h MJ ${ }^{-1} \mathrm{ha}^{-1} \mathrm{~mm}^{-1}$ (SBT1P5, $12 \%$ organic matter). It has to be noticed that in the DS area LS was almost constant. Therefore, a direct effect of the topographic factor on the deposition processes can be excluded. The protection of the avalanche defense structures against soil erosion, slowing down the snow movements in winter, allowed over time the colonization by shrubs and larch seedlings that can locally reduce soil erosion in the vegetative season. A feedback effect can be hypothesized: 


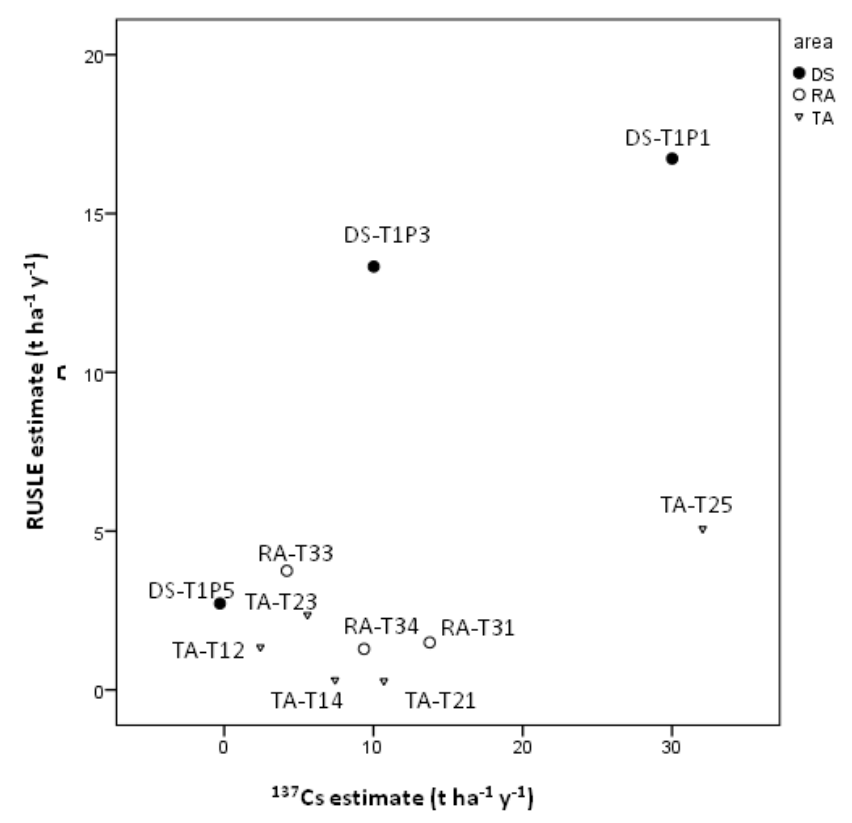

Figure 4. Scatterplot of measured and modeled erosion rates in the study area. DS: defense structures area; TA: track area; RA: release area.

physical barriers induce a reduction in snow gliding, i.e., less soil erosion; natural regeneration is favored, and enhances the protection against erosion; soil organic matter increases; soil erodibility decreases; soil erosion is again reduced.

In general, ${ }^{137} \mathrm{Cs}$ estimates gave higher erosion rates at the sample points than the erosion estimates obtained with RUSLE (Fig. 4). The discrepancies between ${ }^{137} \mathrm{Cs}$ and RUSLE erosion rates obtained in our study are consistent with the ones shown in Konz et al. (2009), who found that ${ }^{137} \mathrm{Cs}$ erosion rates ranged between 5 and $37 \mathrm{tha}^{-1} \mathrm{yr}^{-1}$, while USLE estimates did not exceed $15 \mathrm{tha}^{-1} \mathrm{yr}^{-1}$. When the data set is studied as a whole, no significant correlation is visible between the two variables $(r=0.49$, ns), and an outlier represented by point TA-T25 is clearly evident (Fig. 4). The extreme behavior of point TA-T25 can be easily explained by its LS value (37), the highest in the study area, which can be considered extreme with respect to the remaining points. The differences between estimates do not appear to be related to the variation of a single RUSLE factor such as topography or erodibility.

We observed that most points characterized by limited water erosion potential $\left(1<A<5 \mathrm{tha}^{-1} \mathrm{yr}^{-1}\right)$ because of low $K$ and/or LS factors (DS-T1P5, TA-T12, TA-T14, TA-T21, TA-T23, TA-T25, whole RA) showed ${ }^{137}$ Cs erosion rates more than twice as high compared to $A$ (only exception, RAT33 where $A$ and ${ }^{137}$ Cs estimates were closer). Our hypothesis is that despite the intrinsic soil properties and/or topographic conditions, in these sampling sites the contribution of winter erosion (i.e., avalanche erosion and/or snow gliding) is particularly severe. In fact, literature findings showed
Table 2. Calculated $W$ (winter factor). Negative values correspond to sedimentation rates. DS: defense structures area; TA: track area; RA: release area.

\begin{tabular}{lll}
\hline $\begin{array}{l}\text { Sample } \\
\text { ID }\end{array}$ & $\begin{array}{l}\text { Altitude } \\
(\text { ma.s.1. })\end{array}$ & $\begin{array}{l}W \\
(-)\end{array}$ \\
\hline DS-T1P1 & 2085 & 1.79 \\
DS-T1P3 & 2078 & 0.75 \\
DS-T1P5 & 2060 & -0.11 \\
TA-T12 & 1977 & 1.81 \\
TA-T14 & 2001 & 23.76 \\
TA-T21 & 1956 & 38.54 \\
TA-T23 & 1989 & 2.36 \\
TA-T25 & 2016 & 6.32 \\
RA-T31 & 2099 & 9.21 \\
RA-T33 & 2084 & 1.12 \\
RA T34 & 2070 & 7.25 \\
\hline
\end{tabular}

that the erosion rates determined by avalanche runs can be significant and non-selective, i.e., act independently of soil properties and size classes, but are rather controlled by the depth and velocity of the snow mass (Confortola et al., 2012). This would be applicable to the track area. In RA snow gliding and incipient avalanche movements can be hypothesized, too, and have been documented by Ceaglio et al. (2014), who observed snow glide rates in the order of magnitudes of several meters. The DS area, despite a rather homogeneous LS factor (range 20-23), showed sharp differences in erodibility and a reduction trend along slope that was visible for both RUSLE and ${ }^{137} \mathrm{Cs}$ erosion rates; for the latter a deposition at the bottom of the area was even estimated (Fig. 4). The box plot of Fig. 5a depicts the difference obtained by subtracting $A$ from ${ }^{137} \mathrm{Cs}$ estimates. This difference represents the relative importance of winter erosion (avalanches + snow gliding + snowmelt) with respect to the total average annual erosion budget (estimated with ${ }^{137} \mathrm{Cs}$ ). The median (black horizontal line) is similar for TA and RA, while it drops considerably in DS, suggesting different prevailing snow-induced processes in the DS area, such as the protection effect carried out by defense structures against snow gliding. The discrepancy in RA and TA is much less evident, except for one outlier (TA-T25), characterized by an extreme LS value (Table 1).

The proposed $W$ values (dimensionless) are presented for the sampling points in Table 2. $W$ varied from -0.11 (minus sign indicates deposition at DS-T1P5) to approximately 39 (at TA-T21), with considerable spatial variability. The range of $W$ values for the three considered subareas fell in the range found by Konz et al. (2009), which varied from 0.4 to 17.5 for a mountain environment in Switzerland, where the main snow-induced disturbance was snow gliding.

The box plot in Fig. 5b shows the $W$ distribution in the three subareas. It is clearly visible that the DS area has a median $W$ value less than 1 . On the contrary, TA and RA show 

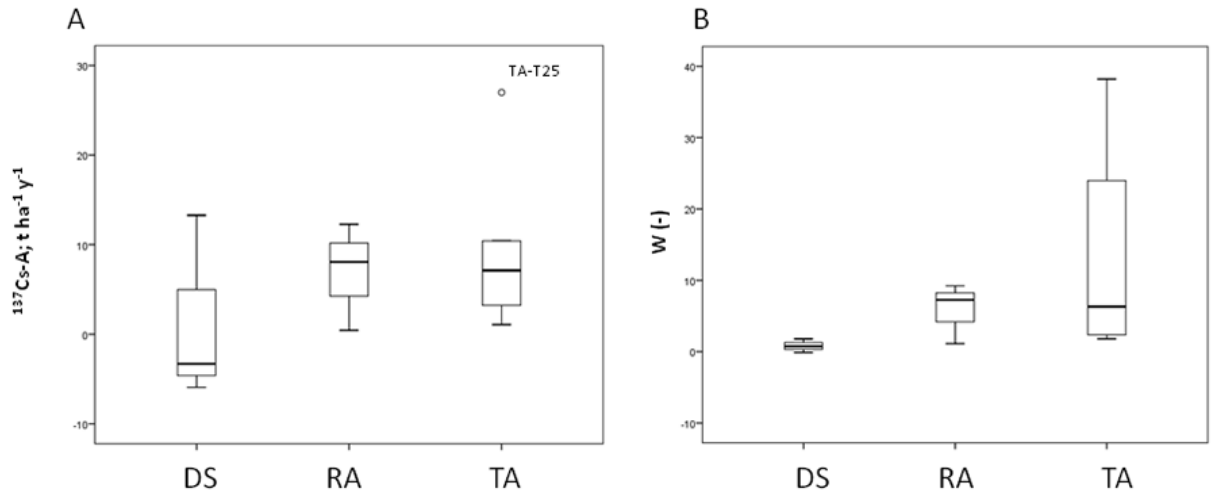

Figure 5. Box plots of (A) the difference between ${ }^{137} \mathrm{Cs}$ and RUSLE estimates $\left({ }^{137} \mathrm{Cs}-A ; \mathrm{tha}^{-1} \mathrm{yr}^{-1}\right)$ and $(\mathbf{B})$ winter factor $(W$, dimensionless) for the three different subareas (RA: release area; DS: defense structures; TA: track area).

similar median values in the range of $5-10$, with extreme cases where $W$ exceeds 20 , and denote some role of winter erosion processes. In TA the variability of the $W$ values was higher, and likely related to the high terrain variability and complex morphology.

We are conscious of the limited number of areas studied, but the pattern observed in the $W$ factor distribution suggests that the differences between erosion estimates can be linked to the prevailing winter dynamics, i.e., the DS area, RA, TA have different behavior because the acting forces vary.

We finally addressed the problem of RUSLE accuracy based on the data reported by Yoder et al. (2001) and Bazzoffi (2007). As a rough consideration, according to Yoder et al. (2001) the accuracy of the RUSLE estimate ( $A$, $\left.\mathrm{tha}^{-1} \mathrm{yr}^{-1}\right)$ is expected to vary depending on the magnitude of $A$, i.e., lower calculated values will have more uncertainty (up to $\pm 50 \%$ ), while higher estimates will have lower uncertainty (up to $\pm 25 \%$ ). Considering this range of variation for the A computed values (reported in Fig. 4), we still observed a higher value for ${ }^{137} \mathrm{Cs}$ estimates, and three $W$ ranges for the three subareas. This is an encouraging result from the practical application of the method proposed.

\subsection{Erosive force estimated with the RAMMS avalanche model}

In order to reinforce this interpretation, the RAMMS avalanche model was applied. The results, extracted for the sampling points considered for $W$ estimation, are presented in Table 3. Points in the release area are not presented because the model performance is not optimal at the very beginning of the avalanche track. The DS area is obviously excluded as it is not affected by avalanches.

Points TA-T12 and TA-T14 (Table 3) show the lowest values of normal $(\sigma)$ and shear $(\tau)$ stress as they are located at the side of the avalanche track, where the flow height $(H)$ and velocity $(U)$ are lower than in the middle of the track, while the remaining points (TA-T21, TA-T23, and TA-T25) are along a transect in the middle of the avalanche path,
Table 3. Output of the RAMMS avalanche model at the sample points ( $H=$ flow height, $U=$ velocity, $\sigma=$ normal stress, $\tau=$ basal shear stress, $T_{\mathrm{c}}=$ critical soil shear stress; TA: track area; RA: release area).

\begin{tabular}{llllll}
\hline Sample ID & $H(\mathrm{~m})$ & $U\left(\mathrm{~m} \mathrm{~s}^{-1}\right)$ & $\sigma(\mathrm{Pa})$ & $\tau(\mathrm{Pa})$ & $T_{\mathrm{c}}(\mathrm{Pa})$ \\
\hline TA-T12 & 0.16 & 10.9 & 401.10 & 278.9 & 1.42 \\
TA-T14 & 0.24 & 14.9 & 563.51 & 472.9 & 1.66 \\
TA-T21 & 1.02 & 20.4 & 2545.9 & 1273.7 & 1.63 \\
TA-T23 & 1.03 & 20.7 & 2396.1 & 1252.8 & 1.55 \\
TA-T25 & 1.23 & 19.8 & 2987.3 & 1353.0 & 1.76 \\
\hline
\end{tabular}

where avalanche bottom shear stresses increased considerably. The shear stress exerted by the avalanche increased with the avalanche velocity and height. The critical shear stress $T_{\mathrm{c}}$ calculated for soil according to the formula proposed by Clark and Wynn (2007) was, with values of 1.42 to $1.76 \mathrm{~Pa}$, in the range of values reported by Confortola et al. (2012) and at least two orders of magnitude lower than the stress exerted by the avalanche with $\tau$ values of 279 to $1353 \mathrm{~Pa}$ (Table 3 ). Therefore, the model generally confirmed that the avalanche action actually produces erosive effects on the soil surface. However, no clear relationship between $W$ and avalanche modeled parameters could be observed (Spearman $r=0.5$ ). This could depend on (a) the small number of points (only 5) that could be considered in the comparison between $W$ and the avalanche modeled parameters, and (b) the impossibility of assessing the relative weight of snow gliding and avalanche erosion rates with the available data. The latter statement is particularly true for points TA-T12 and TA-T14, close to the boundary, where different winter processes, characterized by different intensities, can coexist.

The findings of the present research in terms of $W$ order of magnitude, ranges and patterns seem promising; however, further validation with a larger data set and with punctual measurement of snow cover parameters will be needed to establish the appropriate basis for an adaption of RUSLE to Alpine environments. 


\section{Conclusions}

The application of RUSLE at a study site in the Italian Western Alps prone to snow gliding and glide-snow avalanches was compared with ${ }^{137} \mathrm{Cs}$ method estimates. In general, the ${ }^{137}$ Cs estimates, accounting for all erosion types, were higher than RUSLE estimates that only consider water-induced soil erosion (i.e., erosion taking place on snow-free soil). Such discrepancies suggested a non-negligible effect of winter erosion on the total annual soil loss. While the avalanche defense structures acted as an effective physical barrier, and reduced the snow gliding movements, in the RA and TA a relevant effect of snow-driven erosion was hypothesized, with prevalent snow gliding processes in the case of RA, and prevalent avalanche erosion in TA.

The introduction of a winter correction factor ( $W$ - dimensionless) obtained as the ratio between ${ }^{137} \mathrm{Cs}$ and RUSLE estimates, taking into account winter erosion processes, gave promising results and could serve as a tool for the application of the RUSLE erosion model in mountain areas. The ranges of variation obtained for $W$ evidenced some relevant differences in the role of winter erosion in the considered subareas. In fact, the DS area showed lover $W$ values $(<1)$, and TA and RA showed similar median values (in the range 5-10) with extreme cases where $W$ exceeded 20. The application of the RAMMS avalanche simulation model corroborated these findings. To conclude, despite the limited sample size (11 points) the inclusion of a $W$ factor in RUSLE seems promising for the improvement of soil erosion estimates in Alpine environments affected by snow movements.

Acknowledgements. This research was supported by Italian MIUR project (PRIN 2010-11) "Response of morphoclimatic system dynamics to global changes and related geomorphological hazards" (national coordinator C. Baroni). We would also like to thank the Ufficio Centro Funzionale (Regione Autonoma Valle d'Aosta Assessorato opere pubbliche, difesa del suolo e edilizia residenziale pubblica - Dipartimento difesa del suolo e risorse idriche) for data sets, and the WSL-SLF of Davos $(\mathrm{CH})$ for the use of the "RAMMS" avalanche model.

Edited by: P. Bartelt

Reviewed by: two anonymous referees

\section{References}

Ackroyd, P.: Erosion by snow avalanche and implications for geomorphic stability, Torlesse Range, New-Zealand, Arctic Alpine Res., 19, 65-70, 1987.

Alewell, C., Meusburger, K., Brodbeck, M., and Bänninger, D.: Methods to describe and predict soil erosion in mountain regions, Landsc. Urban Plann., 88, 46-53, 2008.

Bazzoffi, P.: Erosione del suolo e sviluppo rurale. Edagricole, Bologna, 249 pp., 2007.
Bell, I., Gardner, J., and Descally, F.: An estimate of snow avalanche debris transport, Kaghan Valley, Himalaya, Pakistan, Arctic Alpine Res., 22, 317-321, 1990.

Buehler, Y., Christen, M., Kowalski, J., and Bartelt, P.: Sensitivity of snow avalanche simulations to digital elevation model quality and resolution, Annals Glaciol., 52, 72-80, 2011.

Ceaglio, E., Meusburger, K., Freppaz, M., Zanini, E., and Alewell, C.: Estimation of soil redistribution rates due to snow cover related processes in a mountainous area (Valle d'Aosta, NW Italy), Hydrol. Earth Syst. Sci., 16, 517-528, doi:10.5194/hess-16-5172012, 2012.

Christen, M., Kowalski, J., and Bartelt, P.: RAMMS: numerical simulation of dense snow avalanches in three-dimensional terrain. Cold Reg. Sci. Technol., 63, 1-14, 2010.

Clark, L. A. and Wynn, T. M.: Methods for determining streambank critical shear stress and soil erodibility: implications for erosion rate predictions, Am. Soc. Agr. Biol. Eng., 50, 95-106, 2007.

Confortola, G., Maggioni, M., Freppaz, M., and Bocchiola, D.: Modelling soil removal from snow avalanches: a case study in the Italian Alps, Cold Reg. Sci. Technol., 70, 43-52, 2012.

Desmet, P. J. J. and Govers, G.: A GIS Procedure for Automatically Calculating the USLE LS Factor On Topographically Complex Landscapes Units, J. Soil Water Cons., 51, 427-433, 1996.

De Vente, J. and Poesen, J.: Predicting soil erosion and sediment yield at the basin scale: Scale issues and semi-quantitative models, Earth Sci. Rev., 71, 95-125, 2005.

Facchinelli, A., Magnini, M., Gallini, L., and Bonifacio, E.: ${ }^{137} \mathrm{Cs}$ contamination from Chernobyl of soils in Piemonte (North-West Italy): spatial distribution and deposition model, Water, Air Soil Poll., 134, 341-352, 2002.

Freppaz, M., Lunardi, S., Maggioni, M., Valfré, F., Bizzocchi, T., and Zanini, E.: Soil erosion caused by snow avalanches: preliminary results of two case studies in the Aosta Valley (NWItaly), in: Proceeding of the International Snow Science Workshop: a Merging between Theory and Practice (ISSW 2006) Telluride, Colorado, USA, 1-7 October 2006, 880-886, 2006.

Freppaz, M., Godone, G., Filippa, G., Maggioni, M., Lunardi, S., Williams, M. W., and Zanini, E.: Soil Erosion Caused by Snow Avalanches: a Case Study in the Aosta Valley (NW Italy), Arct. Antarct. Alp. Res., 42, 412-421, 2010.

Garcia Rodriguez, J. L., Martin, C., and Gimenez Suarez, C.: Methodology for estimating the topographic factor LS of RUSLE3D and USPED using GIS, Geomorphology, 175-176, 98-106, 2012.

Gardner, J. S.: Observations on erosion by wet snow avalanches, Mount Rae area, Alberta, Canada, Arctic Alpine Res., 15, 271 274, 1983.

Grimm, M., Jones, R. J. A., Rusco, E., and Montanarella, L.: Soil Erosion Risk in Italy: a revised USLE approach. European Soil Bureau Research Report No.11, EUR20677 EN, (2002), 28 pp., Office for Official Publications of the European Communities, Luxembourg, 2003.

Gruber, U. and Bartelt, P.: Snow avalanche hazard modelling of large areas using shallow water numerical methods and GIS, Environmental Model. Softw., 22, 1472-1481, 2007.

Heckmann, T., Wichmann, V., and Becht, M.: Sediment transport by avalanches in the Bavarian Alps revisited - a perspective on modelling, in: Geomorphology in Environmental Application, edited by: Schmidt, K. H., Becht, M., Brunotte, E., Eitel, B., and 
Schrott, L., Zeitschrift für Geomorphologie, Supplement Series, Gebruder Borntraeger, Stuttgart, 11-25, 2005.

Joint Research Center Ispra, Nature and extent of soil erosion in Europe, Commission European Communities, available at: http:// ec.europa.eu/environment/soil/pdf/vol2.pdf (last access: 28 January 2014), 2009.

Jomelli, V. and Bertran, P.: Wet snow avalanche deposits in the French Alps: structure and sedimentology, Geogr. Ann. A, 83, 15-28, 2001.

Konz, N., Schaub, M., Prasuhn, V., Baenninger, D., and Alewell, C.: Cesium-137-based erosion-rate determination of a steep mountainous region, J. Plant Nutr. Soil Sci., 172, 615-622, 2009.

Konz, N., Prasuhn, V., and Alewell, C.: On the measurement of Alpine soil erosion, Catena, 91, 63-71, 2012.

Korup, O. and Rixen, C.: Soil erosion and organic carbon export by wet snow avalanches, The Cryosphere, 8, 651-658, doi:10.5194/tc-8-651-2014, 2014.

Lal, R.: Soil degradation by erosion, Land Degr. Develop., 12, 519539, 2001

Leitinger, G., Höller, P., Tasser, E., Walde, J., and Tappeiner, U.: Development and validation of a spatial snow-glide model, Ecol. Model., 211, 363-374, 2008.

Litschert, S. E., Theobald, D. M., and Brown, T. C.: Effects of climate change and wildfire on soil loss in the Southern Rockies Ecoregion, Catena 118, 206-219, 2014.

Lopez Moreno, J. L., Fassnacht, S. R., Heath, J. T., Musselman, K. N., Revuelto, J., Latron, J., Morán-Tejeda, E., and Jonas, T.: Small scale spatial variability of snow density and depth over complex alpine terrain: Implications for estimating snow water equivalent, Adv. Water Resour., 55, 40-52, 2013.

Mabit, L. and Bernard, C.: Assessment of spatial distribution of fallout radionuclides through geostatistics concept, J. Environ. Radioact., 97, 206-219, 2007.

Mabit, L., Benmansour, M., and Walling, D. E.: Comparative advantages and limitations of the fallout radionuclides ${ }^{137} \mathrm{Cs}$, ${ }^{210} \mathrm{~Pb}(\mathrm{ex})$ and $7 \mathrm{Be}$ for assessing soil erosion and sedimentation, J. Environ. Radioact., 99, 1700-1807, 2008.

Mabit, L., Meusburger, K., Fulajtar, E., and Alewell, C.: The usefulness of ${ }^{137} \mathrm{Cs}$ as a tracer for soil erosion assessment: A critical reply to Parsons and Foster (2011), Earth-Sci. Rev., 127, 300307, 2013.

Matisoff, G. and Whiting, P. J.: Measuring Soil Erosion Rates Using Natural (Be-7, Pb-210) and Anthropogenic (Cs-137, Pu-239,Pu240) Radionuclides, Handbook of Environmental Isotope Geochemistry, Vols. 1 and 2, edited by: Baskaran, M., SpringerVerlag Berlin, Berlin, 487-519, 2011.

Meusburger, K., Konz, N., Schaub, M., and Alewell, C.: Soil erosion modelled with USLE and PESERA using QuickBird derived vegetation parameters in an Alpine catchment, Int. J .Appl. Earth Obs. Geoinf., 12, 208-215, 2010.

Meusburger, K., Steel, A., Panagos, P., Montanarella, L., and Alewell, C.: Spatial and temporal variability of rainfall erosivity factor for Switzerland, Hydrol. Earth Syst. Sci., 16, 167-177, doi:10.5194/hess-16-167-2012, 2012.

Meusburger, K., Leitinger, G., Mabit, L., Mueller, M. H., Walter, A., and Alewell, C.: Soil erosion by snow gliding - a first quantification attempt in a sub-alpine area, Switzerland, Hydrol. Earth Syst. Sci. Discuss., 11, 3675-3710, doi:10.5194/hessd-11-36752014, 2014.
Mitasova, H., Mitas, L., and Brown, W. M.: Multiscale simulation of land use impact on soil erosion and deposition patterns, in: Sustaining the Global Farm, edited by: Stott, D. E., Mohtar, R. H., and Steinhart, G. C., Selected papers from the 10th ISCO Meeting held 24-29 May 1999 at Purdue University and the USDA-ARS NSERL, 1163-1169, 2002.

Prasannakumar, V., Vijith, H., Abinod, S., and Geetha, N.: Estimation of soil erosion risk within a small mountainous subwatershed in Kerala, India, using Revised Universal Soil Loss Equation (RUSLE) and geo-information technology, Geosci. Front., 3, 209-215, 2012.

Prasuhn, V., Linniger, H., Gisler, S., Herweg, K., Candinas, A., and Clement, J. P.: A high-resolution soil erosion risk map of Switzerland as strategic policy support system, Land Use Pol., 32, 281-291, 2013.

Renard, K., Foster, G., Weesies, G., McCool, D., and Yoder, D.: Predicting soil erosion by water: a guide to conservation planning with the Revised Universal Soil Loss Equation (RUSLE), USDA Agriculture Handbook \#703, 384 pp., 1997.

Ritchie, J. C. and McHenry, J. R.: Application of radioactive fallout cesium-137 for measuring soil-erosion and sediment accumulation rates and patterns - A review, J. Environ. Qual., 19, 215-233, 1990.

Salm, B.: Flow, flow transition and runout distances of flowing avalanches, Ann. Glaciol. 18, 221-226, 1993.

Sass, O., Hoinkis, R., and Wetzel, K. F.: A six-year record of debris transport by avalanches on a wildfire slope (Arnspitze, Tyrol), Z. Geomorphol., 54, 181-193, 2010.

Shakhashiro, A. and Mabit, L.: Results of an IAEA intercomparison exercise to assess ${ }^{137} \mathrm{Cs}$ and total $210 \mathrm{~Pb}$ analytical performance in soil, Appl. Radiat. Isot., 67, 139-146, 2009.

Tamura, T.: Selective sorption reaction of caesium with mineral soils, Nucl. Saf., 5, 262-268, 1964.

Tamura, T. and Jacobs, D. G.: Structural implications in cesium sorption, Health Phys., 2, 391-398, 1960.

US Department of Agriculture, S.C.S.: Procedure for Computing Sheet and Rill Erosion on Project Areas. Soil Conservation Service, Technical Release No. 51 (Rev. 2), 1977.

Walling, D. E. and Quine, T. A.: Calibration of caesium-137 measurements to provide quantitative erosion rate data, Land Degrad. Rehabil., 2, 161-173, 1990.

Wischmeier, W. H. and Smith, D. D.: Predicting Rainfall Erosion Losses - A Guide to Conservation Planning, Agric. Handbook No. 537, Washington, DC, 1978.

Yoder, D. C., Foster, G. R., Weesies, G. A., Renard, K. G., McCool, D. K., and Lown, J. B.: Evaluation of the RUSLE soil erosion model, in: Agricultural Non-Point Source Water Quality Models; Their use and Application, edited by: Parsons, J. E., Thomas, D. L., and Huffman, R. L., Southern Cooperative Series Bulletin \#398, July 2001, ISBN: 1-58161-398-9, available at: http://www3.b, 2001.

Zhang, H., Yang, Q., Rui, L., Liu, Q., Moore, D., He, P., Ritsema, C. J., and Geissen., V.: Extension of a GIS procedure for calculating the RUSLE equation LS factor, Comput. Geosci., 52, 177-188, 2013. 